\title{
Dextran and fructose separation on an SMB continuous chromatographic unit
}

\author{
Mariana S. Coelho ${ }^{\mathrm{a}, 1}$, Diana C.S. Azevedo ${ }^{\mathrm{a}, 2}$, José A. Teixeira ${ }^{\mathrm{b}}$, Alírio Rodrigues ${ }^{\mathrm{a}, *}$ \\ ${ }^{a}$ Laboratory of Separation and Reaction Engineering (LSRE), Faculdade de Engenharia da Universidade do Porto, \\ Rua Dr. Roberto Frias s/n, 4200-465 Porto, Portugal \\ ${ }^{\mathrm{b}}$ Departamento de Engenharia Biológica, Campus de Gualtar, 4710-057 Braga, Portugal
}

Received 24 October 2001; accepted after revision 16 May 2002

\begin{abstract}
A dextran/fructose mixture was obtained by fermentation of a sucrose rich media using Leuconostoc mesenteroides NRRL B512(f). The dextran and fructose mixture obtained by fermentation as well as a synthetic mixture of pure components were separated using simulated moving bed (SMB) chromatography. In the case of the synthetic feed, the purity in the raffinate (dextran) and extract (fructose) was 96 and $81 \%$, respectively. For the fermented mixture the purity values were $87.2 \%$ for the extract and $100 \%$ for the raffinate.
\end{abstract}

(C) 2002 Elsevier Science B.V. All rights reserved.

Keywords: Dextran; Fructose; Separation; Chromatography; Simulated moving bed

\section{Introduction}

Separation processes play a critical role in the chemical industry accounting for $40-70 \%$ [15] of the total manufacturing costs in industry and a proper use means a reduction of the costs. Chromatographic processes using simulated moving bed (SMB) technology have been used in the petrochemical industry for almost four decades, mainly for the $p$-xylene separation from a mixture of $\mathrm{C}_{8}$ species. However, in recent years the SMB technology has found a wide spectrum of applications in the pharmaceutical industry and is now a key technology for the separation of enantiomers. Separation costs can be higher than US\$ $200 \mathrm{~kg}^{-1}$ when using HPLC systems [19]. In large-scale production, the use of continuous chromatographic systems, can lead to the reduction of this figure as low as US\$ $0.1 \mathrm{~kg}^{-1}$ [19]. Inherent advantages to this kind of processes are improved flexibility, autonomous operation and constant product quality $[7,8,10]$.

Several authors $[1,9,11-13,17,18]$ have used continuous or semi-continuous adsorbers to study the separation of the mixture glucose/fructose. A system with a countercurrent

\footnotetext{
* Corresponding author. Tel.: +351-2250-81671;

fax: +351-2240-81674.

E-mail address: arodrig@fe.up.pt (A. Rodrigues).

${ }^{1}$ Present address: Departamento de Engenharia Biológica, Campus de Gualtar, 4710-057 Braga, Portugal.

2 Present address: Departamento de Engenharia Química, Universidade Federal do Ceará, Fortaleza, Brazil.
}

moving bed (SMB) allows continuous chromatographic separation.

The objective of this work was to study the continuous separation of the dextran/fructose mixture in an SMB unit. Dextran is a biological polysaccharide produced by microorganism that excrete the enzyme dextransucrase. These $\alpha$-D-glucans (with $95 \%$ of glycosidic linkages $\alpha(1-6)$ ) are the oldest water soluble polysaccharides known to men. Dextrans have a wide range of application, in the pharmaceutical industry and as a substitute for blood plasma [16]. They are also used in the food industry, in photo-film production, as chromatographic media and as soil conditioner [23]. Sucrose is the only known substrate capable of inducing the production of the extracellular enzyme dextransucrase by Leuconostoc mesenteroides NRRL B512(f). Dextransucrase will use the excess sucrose to produce dextran and fructose according to the following equation:

$$
\underset{\text { Sucrose }}{n \mathrm{C}_{12} \mathrm{H}_{22} \mathrm{O}_{11}} \stackrel{\text { Enzyme }}{\rightarrow}\left(\underset{\text { Dextran }}{\left(\mathrm{C}_{6} \mathrm{H}_{10} \mathrm{O}_{5}\right)_{n}}+\underset{\text { Fructose }}{n \mathrm{C}_{6} \mathrm{H}_{12} \mathrm{O}_{6}}\right.
$$

\section{Experimental}

\subsection{Measurement of adsorption equilibrium isotherm for fructose}

The ability of mathematical models to describe the dynamic behaviour of chemical processes depends on the 


\begin{tabular}{|c|c|}
\hline \multicolumn{2}{|c|}{ Nomenclature } \\
\hline$C$ & fluid phase concentration $\left(\mathrm{mol} / \mathrm{m}^{3}\right)$ \\
\hline$C_{\mathrm{el}}$ & $\begin{array}{l}\text { average concentration of the eluent } \\
\text { volume collected in frontal } \\
\text { chromatography experiments } \\
\left(\mathrm{mol} / \mathrm{m}^{3}\right)\end{array}$ \\
\hline$C^{\text {in }}$ & bed inlet concentration $\left(\mathrm{mol} / \mathrm{m}^{3}\right)$ \\
\hline $\bar{C}_{\mathrm{p}}$ & average pore concentration $\left(\mathrm{mol} / \mathrm{m}^{3}\right)$ \\
\hline$D_{\mathrm{ax}}$ & axial dispersion coefficient $\left(\mathrm{m}^{2} / \mathrm{s}\right)$ \\
\hline$k_{\mathrm{p}}$ & $\begin{array}{l}\text { mass transport coefficient in the } \\
\text { pores }\left(\mathrm{s}^{-1}\right)\end{array}$ \\
\hline$k_{\mu}$ & $\begin{array}{l}\text { mass transport coefficient in the } \\
\text { microparticles }\left(\mathrm{s}^{-1}\right)\end{array}$ \\
\hline$K$ & $\begin{array}{l}\text { equilibrium constant for a homogeneous } \\
\text { adsorbent particle (=(moles adsorbed/ } \\
\text { particle volume }) /(\text { moles in bed fluidphase/ } \\
\text { bed void volume) })\end{array}$ \\
\hline$K^{\prime}$ & $\begin{array}{l}\text { equilibrium constant }(=\text { (moles adsorbed/ } \\
\text { particle volume }) /(\text { moles in pore fluid phase } / \\
\text { fluid volume in particle pores) })\end{array}$ \\
\hline$L_{\mathrm{c}}$ & column length (m) \\
\hline$L_{j}$ & zone length (m) \\
\hline$\langle\bar{q}\rangle$ & $\begin{array}{l}\text { particle averaged solid phase concentration } \\
\text { (bi-LDF approximation) (=mole adsorbed/ } \\
\text { particle volume) }\end{array}$ \\
\hline$Q$ & SMB fluid flowrate $\left(\mathrm{m}^{3} / \mathrm{s}\right)$ \\
\hline$Q^{\prime}$ & TMB fluid flowrate $\left(\mathrm{m}^{3} / \mathrm{s}\right)$ \\
\hline$t_{\mathrm{st}}$ & stoichiometric time (s) \\
\hline$t^{*}$ & rotation period $(\mathrm{s})$ \\
\hline$U_{\mathrm{F}}$ & fluid interstitial velocity $(\mathrm{m} / \mathrm{s})$ \\
\hline$U_{\mathrm{S}}$ & solid interstitial velocity $(\mathrm{m} / \mathrm{s})$ \\
\hline$V$ & column volume $\left(\mathrm{m}^{3}\right)$ \\
\hline$V_{\mathrm{el}}$ & eluent volume $\left(\mathrm{m}^{3}\right)$ \\
\hline$V_{\mathrm{ex}}$ & extra-column volume $\left(\mathrm{m}^{3}\right)$ \\
\hline \multicolumn{2}{|c|}{ Greek letters } \\
\hline$\alpha_{\mathrm{p}}$ & $\begin{array}{l}\text { number of macropore mass transfer } \\
\text { units (bi-LDF approximation) }\end{array}$ \\
\hline$\alpha_{\mu}$ & $\begin{array}{l}\text { number of microparticle mass transfer } \\
\text { units (bi-LDF approximation) }\end{array}$ \\
\hline$\varepsilon$ & bed porosity (dimensionless) \\
\hline & particle porosity (dimensionless) \\
\hline$v$ & solid/fluid volume ratio \\
\hline \multicolumn{2}{|l|}{ Subscripts } \\
\hline $1,2,3,4$ & subscripts referring to TMB zones \\
\hline DEX & dextran \\
\hline $\mathrm{F}, \mathrm{R}, \mathrm{E}, \mathrm{X}$ & feed, raffinate, eluent and extract \\
\hline FR & $\begin{array}{l}\text { SMB streams, respectively } \\
\text { fructose }\end{array}$ \\
\hline$i$ & chemical species (fructose or dextran) \\
\hline$j$ & TMB section \\
\hline $\mathrm{p}$ & particle \\
\hline
\end{tabular}

quality of the measurement of various model parameters, in particular the adsorption equilibrium isotherm of the solute on the adsorbent resin used. The frontal chromatographic technique [14] was used to determine the adsorption equilibrium isotherm of fructose (p.a., Merck) on the ion-exchange resin Dowex Monosphere 99/Ca (Rohm and Haas, France).

Dowex Monosphere 99/Ca is a sulphonated resin in $\mathrm{Ca}^{2+}$ form with a mean particle size of $320 \mu \mathrm{m}$ and maximum operation temperature of $120^{\circ} \mathrm{C}$. The column used $\left(2.6 \times 29 \mathrm{~cm}\right.$; volume $\left.154 \times 10^{-3} \mathrm{dm}^{3}\right)$ was a Superformance ${ }^{\circledR}$, Universal glass cartridge system, from Götec Labortechnik (Germany). The column was equipped with a jacket for temperature control.

The adsorption equilibrium isotherm for fructose was studied at $30^{\circ} \mathrm{C}$. The eluent used was deionized and distilled water and the experiments were carried out using four different concentrations for each sugar: 30, 15, 10 and $5 \mathrm{~g} / \mathrm{l}$. The analytical system used was a Gilson HPLC system with a refractive index detector (model 131). The bed was initially saturated with a solute with feed concentration $C^{\text {in }}$ (g/l) and then was eluted with water. The eluent volume $V_{\mathrm{el}}$ (1) was collected and the average concentration of sugar $C_{\mathrm{el}}$ ( $g / l)$ was measured. To calculate the adsorbed quantity of sugar in the column the following mass balance was made:

$V_{\mathrm{el}} C_{\mathrm{el}}=\varepsilon C_{\mathrm{in}} V+(1-\varepsilon) q_{\mathrm{in}} V+C_{\mathrm{in}} V_{\mathrm{ex}}$

where $\varepsilon$ is the bed porosity, $V$ the column volume (l), $V_{\text {ex }}$ accounts for any extra-column volume (1) and $q^{\text {in }}$ the adsorbed concentration in equilibrium $(\mathrm{g} / \mathrm{l})$ with the fluid concentration $C^{\text {in }}(\mathrm{g} / \mathrm{l})$.

Table 1 shows results for fructose frontal chromatography. The adsorbed concentration is calculated in grams of sugar adsorbed per litre of resin in the column. A bulk porosity of 0.4 was considered, as obtained from tracer experiments using blue dextran [2].

Fig. 1 shows a linear adsorption isotherm for fructose at $30^{\circ} \mathrm{C}$. The adsorption equilibrium constant is 0.53 , as obtained from the average of the values found in the column $q^{\text {in }} / C^{\text {in }}$. This isotherm is in good agreement with the results of Altenhõner et al. [3] for fructose adsorption on a similar resin.

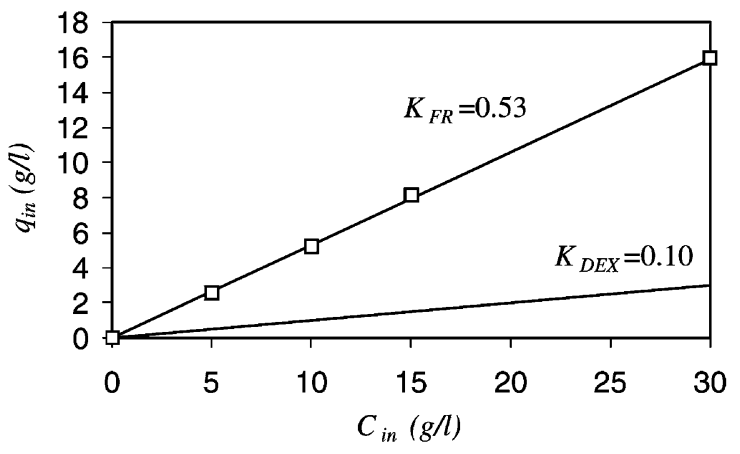

Fig. 1. Adsorption isotherm of fructose on Dowex Monosphere 99/Ca at $30^{\circ} \mathrm{C}$. 
Table 1

Adsorption results for experiments carried out with fructose at $30^{\circ} \mathrm{C}$

\begin{tabular}{|c|c|c|c|c|c|}
\hline$C^{\text {in }}$ (g fructose/l fluid) & $\begin{array}{l}\text { Eluted } \\
\text { volume }(\mathrm{ml})\end{array}$ & $\begin{array}{l}\text { Average eluted } \\
\text { concentration }(\mathrm{g} / \mathrm{l})\end{array}$ & Eluted mass (g) & $q^{\text {in }}(\mathrm{g}$ fructose $/ 1$ solid $)$ & $q^{\mathrm{in}} / C^{\mathrm{in}}$ \\
\hline 5 & 539.37 & 1.02 & 567.8 & 2.57 & 0.51 \\
\hline 10 & 576.89 & 1.92 & 632.1 & 5.22 & 0.52 \\
\hline 15 & 502.97 & 3.39 & 534.2 & 8.15 & 0.54 \\
\hline 30 & 556.35 & 6.03 & 632.1 & 15.96 & 0.53 \\
\hline
\end{tabular}

\subsection{Pulse experiment with dextran}

In order to determine the constant of adsorption of dextran on the resin (assumed as linear), a pulse of dextran solution $(5 \mathrm{~g} / \mathrm{l})$ was injected into the column as in a tracer experiment. It is possible to calculate the adsorption constant from the stoichiometric time of the pulse obtained at the exit of the column according to the following equation:

$t_{\mathrm{st}}=\frac{V}{Q}\left(\varepsilon+(1-\varepsilon) K_{\mathrm{DEX}}\right)$

where $Q$ is the fluid flowrate $(1 / \mathrm{min})$. Fig. 2 shows the obtained column response to a pulse of dextran $(200 \mathrm{mi}-$ croliter) under a flowrate of $5 \times 10^{-3} 1 / \mathrm{min}$. The corresponding adsorption constant $K_{\text {DEX }}$ obtained from Eq. (2) was 0.1 . This value is practically identical to the void fraction of this kind of resin. Hence, dextran only penetrates in the pores of the resin, while the figure 0.1 is a "pseudo"-adsorption constant for a homogeneous adsorbent particle.

Other kinetic parameters for mass transfer and axial dispersion that were used as input in the SMB process model are summarized in Table 3 as they have been reported by Azevedo and Rodrigues [2].

\subsection{Dextran/fructose mixtures preparation}

Two kinds of dextran/fructose mixtures were tested on the SMB pilot unit. The first one to be tested was a mixture prepared using pure species with concentrations of $5 \mathrm{~g} / \mathrm{l}$ for fructose (Merck) and dextran (D-5501 from Sigma).

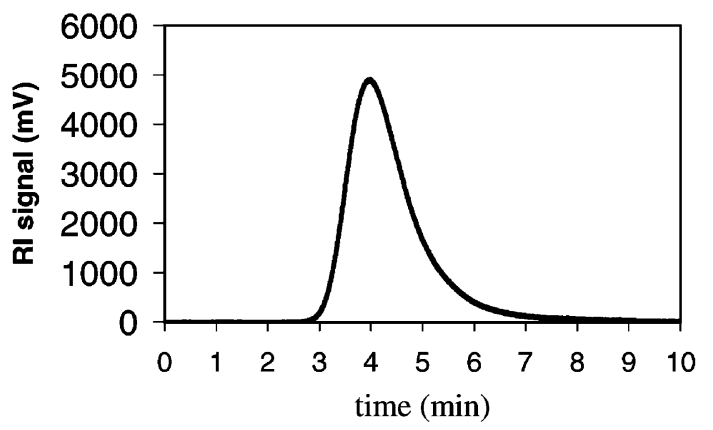

Fig. 2. Concentration response at the exit of a Superformance column $\left(2.6 \times 8.5 \mathrm{~cm}, D_{\mathrm{c}} \times L_{\mathrm{c}}\right)$ to the injection of a $0.2 \mathrm{ml}$ pulse of dextran under a flowrate of $5 \mathrm{ml} / \mathrm{min}$.
The second dextran/fructose mixture was produced by fermentation of sucrose using L. mesenteroides NRRL B512(f) described in previous work [21,22]. L. mesenteroides is a lactic acid bacteria that uses sucrose as substrate to grow and produce an extracellular enzyme dextransucrase. This enzyme also uses sucrose to produce dextran and fructose.

At the end of the fermentation, after removing cells by centrifugation, the broth was still very rich in sodium ions $\left(\mathrm{Na}^{+}\right)$. The resin used in this work is in calcium form; therefore its efficiency will be affected since $\mathrm{Na}^{+}$can replace $\mathrm{Ca}^{2+}$.

In order to remove sodium ions from the fermentation broth, fermentations were carried out with lower concentration of $\mathrm{Na}_{2} \mathrm{HPO}_{4}$ in the culture media $(4 \mathrm{~g} / \mathrm{l})$ instead of $8 \mathrm{~g} / \mathrm{l}$. The fermentation took three more hours but the same product concentrations were obtained (dextran, $8.1 \mathrm{~g} / \mathrm{l}$; fructose, $7.8 \mathrm{~g} / \mathrm{l})$.

Sodium ion concentrations in the solution were determined before and after the fermentation (using a flame photometer DR LANGE 131), where 0.087 and 0.069 equiv./l, respectively; calcium ion concentrations were 0.00052 and 0.00055 equiv./l before and after fermentation, respectively.

Since the total amount of sodium ions present in the culture media after fermentation is still higher than acceptable, it is necessary to remove $\mathrm{Na}^{+}$prior to SMB separation. In the following step, a $500 \mathrm{ml}$ column was filled with an ion-exchange resin Dowex Monosphere 99/Ca (Rohm and Haas, France) in calcium ion form. The broth in batch steps of $250 \mathrm{ml}$ each was passed through the column to exchange the sodium in the liquid with the calcium ions from the resin. Between each batch, the column was washed with distilled water and regenerated to calcium form using a $\mathrm{CaCl}_{2} \quad 10 \%$ solution. The fermented broth after being passed through the column was again analysed for sodium and calcium ions. Measured concentrations were $\left[\mathrm{Na}^{+}\right]=0.011$ equiv./l and $\left[\mathrm{Ca}^{2+}\right]=0.099$ equiv./1.

After this step the final broth concentration in dextran and fructose was 4.98 and $4.82 \mathrm{~g} / \mathrm{l}$, respectively. The fermented broth was constituted of $90 \%$ calcium ions with respect to sodium ions.

\section{Dextran/fructose separation by SMB}

Chromatographic discontinuous separation of dextran/ fructose mixtures was studied by Zafar and Barker [24]. 
Later, Barker et al. [4,5] produced and purified the enzyme dextransucrase and combined reaction and separation on the same chromatographic unit. The aim of this work was to recover dextran and fructose directly from the fermented broth free of cells.

The extraction of dextran produced during the fermentation of L. mesenteroides NRRL B512(f) can be made by alcoholic precipitation [6] which requires large amount of solvent and fructose is not recovered in the same step, being often discarded.

The separation of this kind of mixture is very interesting because we can continuously obtain one extract stream rich in fructose and one raffinate stream rich in dextran. The fluid flowrates in the four sections of the SMB as well as the pseudo-solid flowrate (or the switching time, $t^{*}$ ) must be carefully chosen so that the concentration front of the strongly and weakly adsorbed species move towards the extract and raffinate ports, respectively. Having the equivalent true moving bed (TMB) representation in mind, for linear adsorption isotherms, the fluid-solid velocity ratios must conform to the following constraints [20]:

$\gamma_{1}>v K_{\mathrm{FR}}=1.5 \times 0.53=0.80$

$0.15=\nu K_{\mathrm{DEX}}<\gamma_{2}<\gamma_{3}<\nu K_{\mathrm{FR}}=0.80$

$\gamma_{4}<v K_{\mathrm{DEX}}=1.5 \times 0.1=0.15$

where

$v=\frac{1-\varepsilon}{\varepsilon} \quad$ and $\quad \gamma_{j}=\left.\frac{U_{\mathrm{F}_{j}}}{U_{\mathrm{S}}}\right|_{\mathrm{TMB}}=\left.\frac{Q_{j} t^{*}}{\varepsilon V}\right|_{\mathrm{SMB}}-1$

Fig. 3 shows the relative motion that two chemical species A and $B$ must have in the solid and fluid phases of an equivalent TMB for separation to occur. A is the strongly adsorbed component, fructose. It must be adsorbed by the resin in Sections 2 and 3 and be completely desorbed in Section 1 so as not to contaminate the raffinate and be collected at high purity in the extract. These statements are represented in the constraints expressed in Eqs. (3) and (4). B is the least adsorbed component, dextran. It must flow with the fluid phase in Sections 2 and 3 and be adsorbed in Section 4 in order not to contaminate the recycled eluent and hence, the extract. However, dextran is not adsorbed at all, so that the

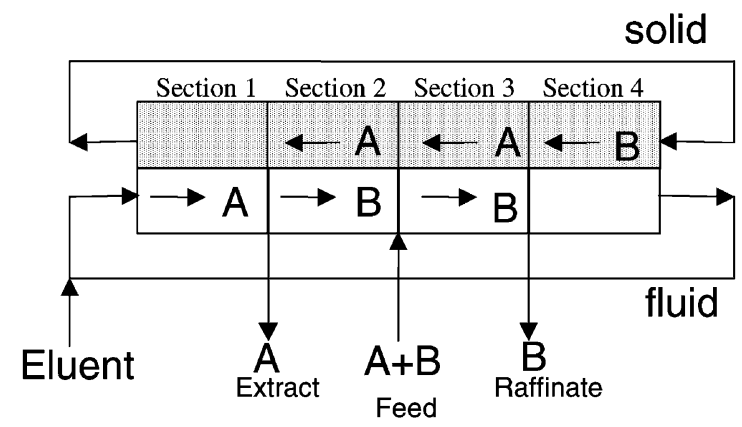

Fig. 3. Representation of a TMB with the relative motion of chemical species $\mathrm{A}$ and $\mathrm{B}$ required for separation.

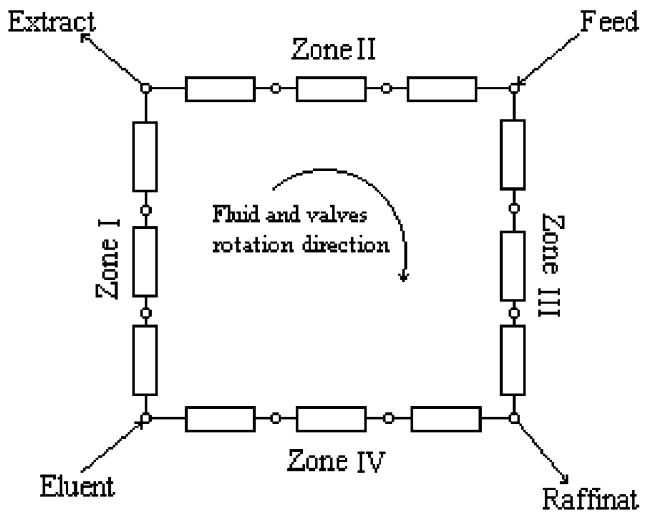

Fig. 4. Representation of an actual SMB.

velocity ratio in Section 4 must be zero. This means that the switching time must be chosen so that it is lower than the space-time of a column under the flowrate in Section 4 $\left(\varepsilon V / Q_{4}^{\mathrm{SMB}}\right)$.

In this separation, 12 columns $2.6 \times 29 \mathrm{~cm}$ were used on an SMB unit Licosep 12-26 from NovaSep (Pompey, France). Fig. 4 shows a scheme of the equipment. The position of the inlet (eluent and feed) and outlet (raffinate and extract) streams is periodically shifted one bed ahead in the direction of the fluid recycling flow. This is achieved by the synchronous actuation of on-off valves so that a countercurrent motion of the solid adsorbent is simulated.

A first experiment was carried out with the mixture prepared from pure fructose $(5.0 \mathrm{~g} / \mathrm{l})$ and dextran $(5.0 \mathrm{~g} / \mathrm{l})$. The mobile phase (eluent) was deionized and distilled water. The operating conditions were determined based on the constraints given in Eqs. (3)-(5) and on the technical limitations of the equipment. They are described in Table 2. The figures in parenthesis indicate the minimum/maximum bounds for each velocity ratio $\gamma_{j}$. Note that the constraint on the velocity ratio in Section 4 was slightly violated due to limitations imposed by the equipment recycling pump. Nevertheless, numerical simulation of the process predicts acceptable separation (>90\%) for dextran, which is the target species of the mixture. Details of this process model may be found elsewhere [1]. Table 3 shows the model equations used.

Fig. 5 presents internal concentration profiles sampled at a half period of the 15th cycle, when cyclic steady state has been reached. This was verified by monitoring the average product concentrations cycle by cycle. Experimental purity reached $96 \%$ for the raffinate and $85.4 \%$ for the extract.

Table 2

Operating conditions for experiments carried out on SMB unit ${ }^{\mathrm{a}}$

\begin{tabular}{ll}
\hline Inlet/outlet flowrates & Internal flowrates/velocity ratios \\
\hline Eluent, $13.92 \mathrm{ml} / \mathrm{min}$ & $Q_{1}=37.92 \mathrm{ml} / \mathrm{min}, \gamma_{1}=0.85(>0.80)$ \\
Extract, $13.07 \mathrm{ml} / \mathrm{min}$ & $Q_{2}=24.85 \mathrm{ml} / \mathrm{min}, \gamma_{2}=0.21(>0.15)$ \\
Raffinate, $3.93 \mathrm{ml} / \mathrm{min}$ & $Q_{3}=27.93 \mathrm{ml} / \mathrm{min}, \gamma_{3}=0.36(<0.80)$ \\
Feed, $3.08 \mathrm{ml} / \mathrm{min}$ & $Q_{4}=24.0 \mathrm{ml} / \mathrm{min}, \gamma_{4}=0.17(<0.15)$ \\
\hline
\end{tabular}

${ }^{\mathrm{a}} t^{*}=3 \min ; T=30^{\circ} \mathrm{C}$. 
Table 3

Process model equations and parameters used in the simulations

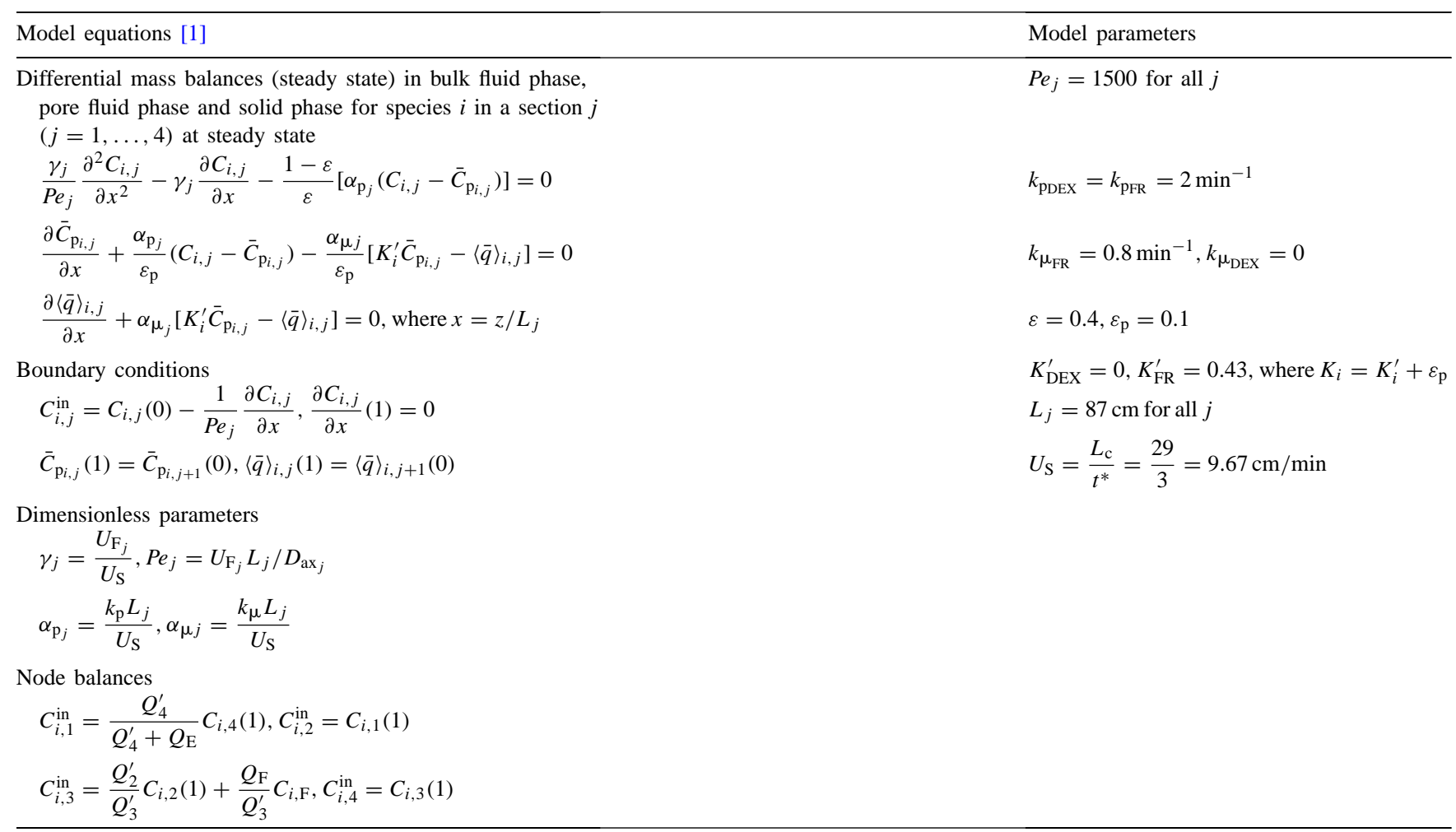

Purity is defined as

$\mathrm{PX}=\frac{\mathrm{Fr}}{\mathrm{Fr}+\mathrm{Dx}} \times 100, \quad \mathrm{PR}=\frac{\mathrm{Dx}}{\mathrm{Fr}+\mathrm{Dx}} \times 100$

where Fr and Dx are the concentrations ( $g / 1)$ of fructose and dextran in the extract and raffinate streams, respectively, when the cyclic steady state has been reached. As expected, quite high purity for the raffinate stream is obtained but

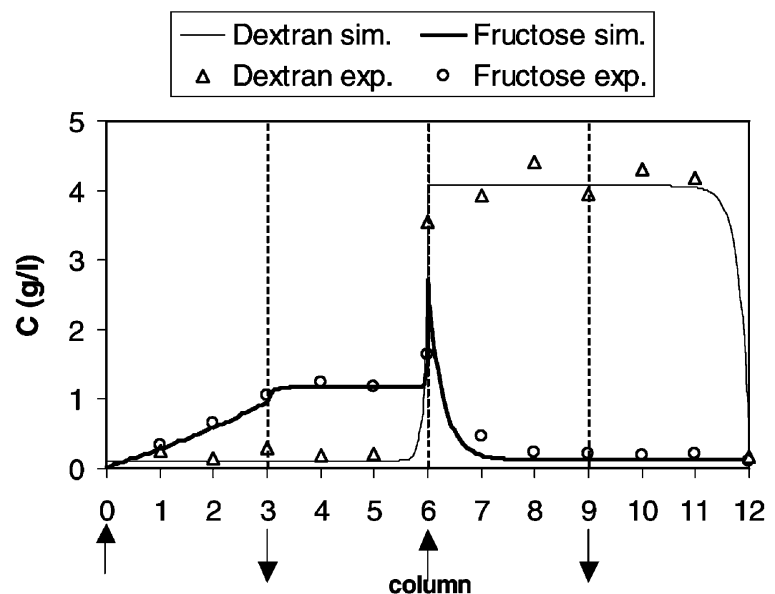

Fig. 5. Concentration profiles of fructose and dextran at cyclic steady state (15th cycle) for the SMB experiment using a synthetic mixture as feed. Symbols are experimental points sampled at $50 \%$ of each period of the cycle and curves are simulations from a TMB-based model. dextran is not completely confined to Section 4 and contaminates the recycled eluent and hence the extract stream. The purities predicted from simulation are 97.1 and $89.5 \%$ for the raffinate and extract streams, respectively. The greatest discrepancy was observed for the extract purity. This is explained by the fact that this stream is quite diluted (around $1 \mathrm{~g} / \mathrm{l}$ ) and thus, any traces of dextran may lead to large variations in the calculated purity of fructose.

In a second SMB experiment, the fermented dextran/fructose mixture was used as feed under the same conditions as stated in Table 2. The feed concentration was 4.98 and $4.82 \mathrm{~g} / \mathrm{l}$ for dextran and fructose, respectively. For this separation, 100 and $87.2 \%$ purities were obtained in raffinate and extract, respectively. Fig. 6 presents internal concentration profiles sampled at a half period of the 15 th cycle, when cyclic steady state has been reached. A summary of the results obtained for both experiments are shown in Table 4.

Table 4

Purities found for dextran/fructose separation on an SMB unit

\begin{tabular}{lclll}
\hline Mixture & $\begin{array}{l}\mathrm{PR}_{\exp } \\
(\%)\end{array}$ & $\begin{array}{l}\mathrm{PX}_{\exp } \\
(\%)\end{array}$ & $\begin{array}{l}\mathrm{PR}_{\text {sim }} \\
(\%)\end{array}$ & $\begin{array}{l}\mathrm{PX}_{\text {sim }} \\
(\%)\end{array}$ \\
\hline $\begin{array}{l}\text { Synthetic dextran/fructose } \\
\text { mixture }\end{array}$ & 96 & 85.4 & 97.1 & 89.5 \\
$\begin{array}{l}\text { Fermented dextran/fructose } \\
\text { mixture }\end{array}$ & 100 & 87.2 & 97.2 & 88.9 \\
\hline
\end{tabular}



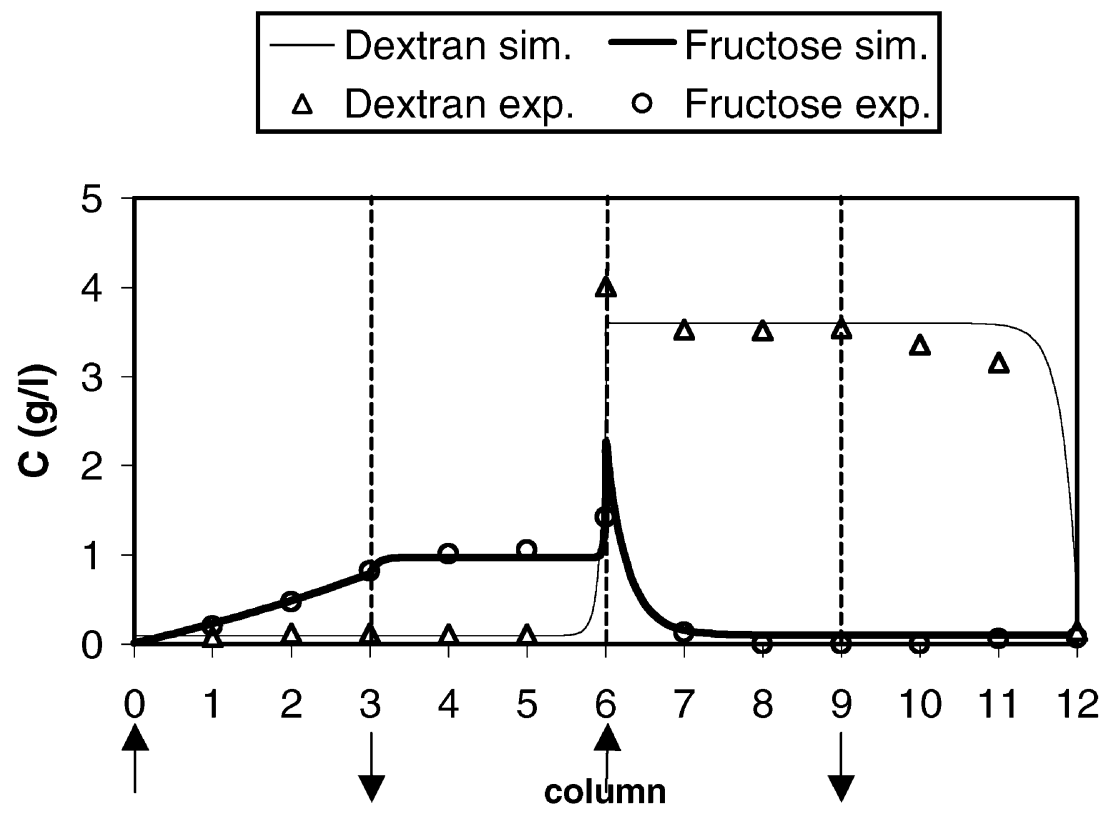

Fig. 6. Concentration profiles of fructose and dextran at cyclic steady state (15th cycle) for the SMB experiment using a fermented mixture as feed. Symbols are experimental points sampled at $50 \%$ of each period of the cycle and curves are simulations from a TMB-based model.

The total volume of resin used (1.111) was much lower than the 11.51 reported by Nicoud [19], who obtained better extract purities as well. Barker et al. [4] also found better results for purity using resin particles with higher mean diameter $(450 \mu \mathrm{m})$ than the one used in this work $(320 \mu \mathrm{m})$; particle size is an important factor in scale-up since we are separating a high molecular weight biopolymer.

\section{Conclusions}

With respect to dextran/fructose separation by SMB chromatography no significant difference was observed on the results obtained for the pure and the fermented mixture. Although the presence of $\mathrm{Na}^{+}$in the fermented broth accounted for $10 \%$, the resin performance was not affected because of its high affinity for $\mathrm{Ca}^{2+}(90 \%)$.

For the synthetic dextran/fructose mixture, 96 and $85.4 \%$ purity was reached for raffinate and extract, respectively. With fermented dextran/fructose mixture, the purity obtained was 100 and $87.2 \%$ also for raffinate and extract, respectively.

To improve dextran/fructose separation for higher concentrations and knowing that dextran is a high molecular weight product it should be used as a resin with a higher mean particle diameter [4].

Another important factor influencing the separation efficiency is the violation of the restriction on the velocity ratio set in Section 4. Because $\gamma_{4}$ used in both experiments is higher than the minimum equilibrium bound, the recycled eluent is contaminated with dextran, which decreases the extract purity. Since the equipment was already operated in the lower limit of flowrates in Section 4, this problem could be overcome by using longer columns, provided that the constraints on the other sections are also observed.

\section{References}

[1] D.C.S. Azevedo, A.E. Rodrigues, Bi-linear driving force approximation in the modeling of simulated moving bed using bidisperse adsorbents, Ind. Eng. Chem. Res. 38 (1999) 3519-3529.

[2] D.C.S. Azevedo, A.E. Rodrigues, Obtainment of high-fructose solutions from cashew (Anacardium occidentale) apple juice by SMB chromatography, Sep. Sci. Technol. 35 (2000) 2561-2581.

[3] U. Altenhõner, M. Meurer, J. Strube, H. Schmidt-Traub, Parameter estimation for the simulation of fluid-chromatography, in: Proceedings of Prep'96, 1996.

[4] P. Barker, G. Ganetsos, J. Ajongwen, A. Akyntoye, Bioreactionseparation on continuous chromatographic systems, Chem. Eng. J. 50 (1992) 23-28.

[5] P. Barker, G. Ganetsos, J. Ajongwen, A novel approach to the production of clinical grade dextran, J. Chem. Technol. Biotechnol. 57 (1993) 21-26.

[6] A. Bell, X. Alvarez, M. Aguilera, Estudio de las propriedades de la dextrana, ICIDCA 2 (2) (1968) 47-55.

[7] D.B. Broughton, Molex: case history of a process, Chem. Eng. Prog. 64 (8) (1968) 60-65.

[8] D.B. Broughton, R.W. Neuzil, J.M. Pharis, C.S. Brearley, The Parex process for recovering para-xylene, Chem. Eng. Prog. 64 (8) (1970) $60-65$.

[9] C.B. Ching, A theoretical model for de simulation of the operation of the semi-continuous chromatographic refiner for separating glucose and fructose, J. Chem. Eng. Jpn. 16 (1) (1983) 49-53.

[10] C.B. Ching, D.M. Ruthven, K. Hidajat, Experimental study of a simulated counter-current adsorption system. III. Sorbex operation, Chem. Eng. Sci. 40 (8) (1985) 1411-1417.

[11] C.B. Ching, D.M. Ruthven, An improved adsorption process for the production of high-fructose syrup, AIChE J. 32 (11) (1986) 1876-1880. 
[12] K. Hashimoto, S. Adachi, H. Noujima, Y. Ueda, A new process combining adsorption and enzyme reaction for producing higher fructose syrup, Biotechnol. Bioeng. 25 (1983) 2371-2393.

[13] K. Hashimoto, S. Adachi, H. Noujima, H. Maruyama, Models for the separation of glucose/fructose mixture using a simulated moving bed adsorber, J. Chem. Eng. Jpn. 16 (5) (1983) 400-406.

[14] F. Helfferich, Ion Exchange, McGraw-Hill, New York, 1962.

[15] J.L. Humphrey, G.E. Keller, Separation Process Technology, McGraw-Hill, New York, 1997.

[16] H.J. Koepsell, H.M. Tsuchiya, Enzymatic synthesis of dextran, J. Bact. 63 (1952) 293-295.

[17] M. Lameloise, V. Viard, Modelling and simulation of a glucose-fructose simulated moving bed adsorber, Trans. IChemE 71 (1993) 27-32.

[18] M. Lukác, Z. Perina, A dynamic model of physical processes in chromatographic glucose-fructose separation, Chem. Eng. Sci. 46 (4) (1991) 959-965
[19] R.M. Nicoud, The simulated moving bed: a powerful chromatographic process, LC-GC INTL 5 (5) (1995) 43-47.

[20] D. Ruthven, Principles of adsorption and adsorption processes, J. Wiley, New York, 1984.

[21] M. Santos, J. Teixeira, A. Rodrigues, Production of dextransucrase, dextran and fructose from sucrose using Leuconostoc mesenteroides NRRL B512(f), Biochem. Eng. J. 4 (2000) 177-188.

[22] M. Santos, Produção de Dextrano e Frutose a partir da Sacarose com Leuconostoc mesenteroides NRRL B512 (f), Ph.D. Thesis, University of Porto, Porto, 1999, 309 pp.

[23] T.R. Shamala, M.S. Prasad, Preliminary studies on the production of high and low viscosity dextran by Leuconostoc spp, Proc. Biochem. 30 (1995) 237-241.

[24] I. Zafar, P.E. Barker, An experimental and computational study of a biochemical polymerisation reaction in a chromatographic reactor separator, Chem. Eng. Sci. 43 (9) (1988) 2369-2375. 